\title{
AVALIAÇÃO DE FERRAMENTA REVESTIDA ATRAVÉS DO PROCESSO DE ASPERSÃO TÉRMICA HVOF *
}

\author{
Vanessa Moura de Souza ${ }^{1}$ \\ Angela Selau Marques ${ }^{2}$ \\ Jorge Antônio Huff ${ }^{3}$ \\ Alexandre da Silva Rocha ${ }^{4}$
}

\section{Resumo}

Os avanços tecnológicos e a busca por peças cada vez mais leves tem levado as empresas a fabricarem peças mais complexas e com menor custo. Porém, para conciliar a alta produtividade com peças complexas é necessário ter um ferramental de qualidade. Sendo assim, a tecnologia de construção de matrizes é um fator fundamental para determinação da eficiência de um processo de forjamento, por exemplo. Tanto variáveis relacionadas ao desempenho financeiro como requisitos de qualidade são influenciados pelo desempenho das matrizes. Em função disto, o foco deste estudo é investigar formas de aumentar a durabilidade das matrizes, com o objetivo de diminuir o desgaste das ferramentas, utilizadas no processo de forjamento a quente, através da deposição de um filme sobre as matrizes. Este trabalho apresenta uma avaliação de desempenho de matrizes de forjamento a quente revestidas por aspersão térmica realizado junto a uma linha de produção. O processo utilizado foi o High Velocity Oxy-Fuel com a deposição de um revestimento de Carboneto de Tungstênio. Previamente foi realizada uma caracterização metalúrgica da camada, com o objetivo de obter informações de referência que auxiliem na interpretação dos resultados dos testes práticos. A ferramenta com o revestimento obteve um aumento de produtividade de aproximadamente $37,5 \%$ além de melhores resultados de estabilidade dimensional ao longo do processo e no acabamento das gravações de identificação nas peças forjadas.

Palavras-chave: Forjamento a quente; Revestimentos; HVOF.

\section{ANALYSIS OF FORGING DIES COATED THROUGH HVOF PROCESS \\ Abstract}

Technological advances and the research for ever lighter parts has forced companies to manufacture more complex parts at a lower cost. But to combine high productivity with complex parts, there is a need for tools with high quality. Thus, the die manufacturing technology is a key factor to determine the efficiency of a forging process. Both variables related to financial performance and quality requirements are influenced by the dies performance. Due to this, the focus of this study is to investigate ways to increase the life of hot forging tools, by decreasing wear through the use of a specific coating. This paper presents a performance evaluation of thermal spraying coated hot forging dies conducted in a production line. The High Velocity Oxy-Fuel process was used for the deposition of a tungsten carbide coating. A metallurgical characterization of the layer was previously done, in order to obtain reference information to assist in the interpretation of the practical tests results. The coated tool allowed a productivity improvement of around $37.5 \%$, besides better dimensional stability results during the whole process and better legibility of the printed identification on the forged parts.

Keywords: Hot Forging; Coatings; HVOF.

1 Engenheira Mecânica, Mestranda, Processos de Fabricação, Universidade Federal do Rio Grande do Sul (UFRGS), Porto Alegre, RS, Brasil.

2 Tecnóloga em Fabricação Mecânica, Mestre, Professora, Processos de Fabricação, Instituto Federal Sul- Riograndense, Sapiranga, RS, Brasil.

3 Engenheiro Metalúrgico, Mestre, Assessor Técnico, Tecnologia de Processos e Produtos, Gerdau, Cosigua, RJ, Brail.

4 Engenheiro Mecânico, Doutor, Professor, Processos de Fabricação, UFRGS, Porto Alegre, RS, Brasil. 


\section{INTRODUÇÃO}

As forjarias necessitam grande flexibilidade de produção, trabalhando geralmente com uma variedade de produtos devido o atual mercado ser muito dinâmico e competitivo. Esta realidade consequentemente influencia as estratégias de trabalho em relação à produção das ferramentas para o processo de conformação. Os revestimentos são utilizados para elevar a resistência ao desgaste e tem como objetivo aumentar a vida útil destas ferramentas [1]. A técnica utilizada para realizar este processo chama-se aspersão térmica, que é um grupo de processos onde materiais metálicos ou não metálicos, finamente divididos, são depositados em uma condição fundida sob uma peça preparada, formando um depósito aspergido [2]. Conforme mostra, de forma representativa a Figura 1.

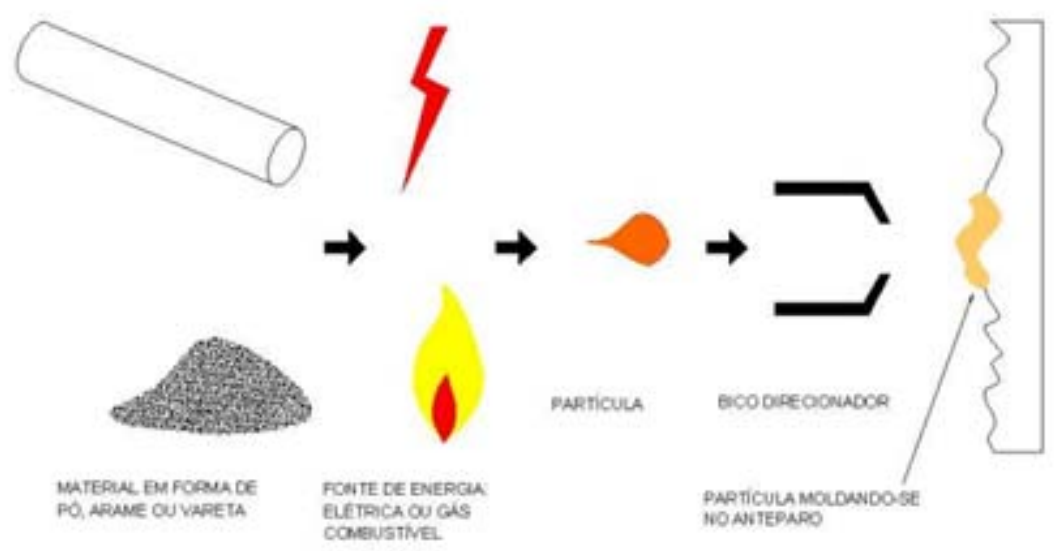

Figura 1. Esquema de aplicação do processo de aspersão térmica.

O material de revestimento pode estar na forma de pó, vareta, cordão ou arame. Existem diversos processos para deposição de filmes duros e eles são classificados conforme o tipo de aquecimento: por combustão ou por eletricidade, conforme mostra a Figura 2.

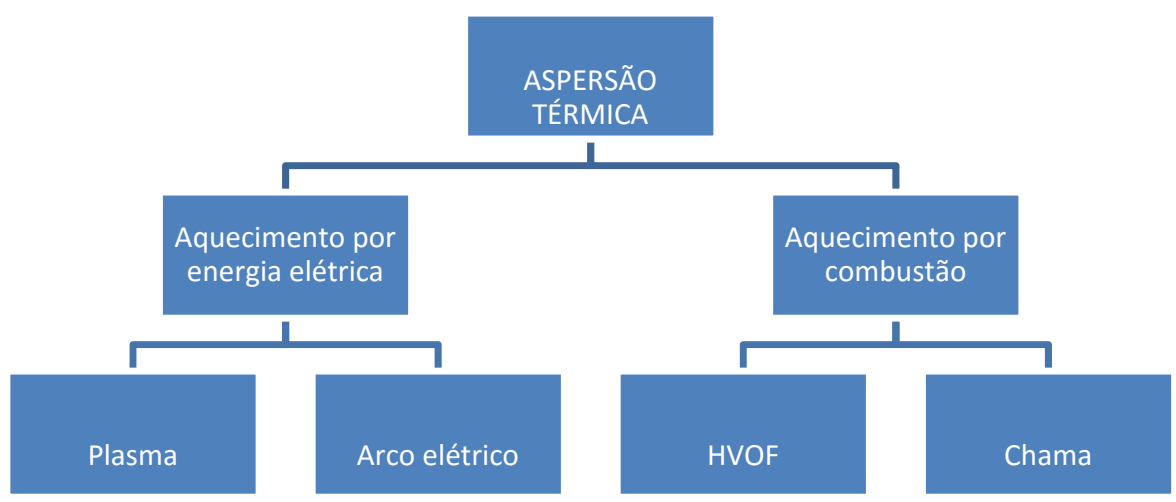

Figura 2. Classificação da aspersão térmica.

Cada processo possui suas particularidades e variações que promovem diferentes condições de aplicação e processamento dos revestimenmtos, modificando suas propriedades [3]. Neste artigo dar-se-á enfase ao HFVO, foco deste estudo e dos experimentos realizados.

O processo de aspersão térmica por High Velocity Oxy-Fuel (HVOF) possui importantes vantagens em comparação com os outros processos de aspersão, além 
de funcionar através de uma pistola que proporciona grande mobilidade e não requer câmaras com ambiente controlado, dentre as quais é possível citar [4]:

$\checkmark$ Baixo ataque térmico ao substrato;

$\checkmark$ Possibilidade de deposição de diversos revestimentos com elevada adesão;

$\checkmark$ Baixa porosidade em comparação com os outros processos de aspersão.

Este processo é desenvolvido pela empresa Rijeza, localizada no município de São Leopoldo/RS. A Figura 3 nos mostra exemplos de peças que estão sendo revestidas com o HVOF. Este processo garante as peças baixa porosidade, inferior à $1 \%$, e com alta adesão ao substrato.

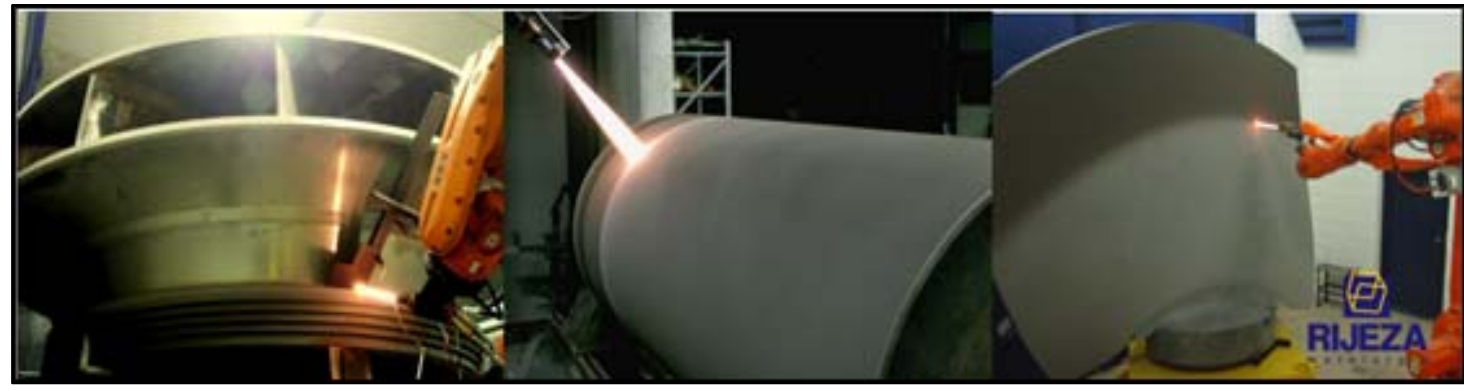

Figura 3. Exemplo de peças com revestimento HVOF.

Os processos de aspersão térmica estão diretamente relacionados com a temperatura e a velocidade das partículas. Na Figura 4 podemos ver a representação das partículas do revestimento quando aspergida sobre o substrato, além disso, é possível verificar a estrutura lamelar de óxidos, inclusões, poros e vazios que também ocorrem durante a deposição [5].

As partículas aspergidas aderem ao substrato por mecanismo de natureza químicometalúrgica, física e mecânica, dependendo da temperatura de fonte de calor e da velocidade imposta às partículas que pelas sucessivas deposições formam camadas lamelares com óxidos e poros. A estrutura dos revestimentos aplicados por aspersão térmica é formada por lamelas sobrepostas, que são oriundas do espelhamento das partículas do pó fundidas, quando do impacto com o substrato. O revestimento é formado pela ocorrência do mesmo mecanismo nas camadas subsequentes, pois o tempo de solidificação é muito menor que o tempo de projeção das partículas.

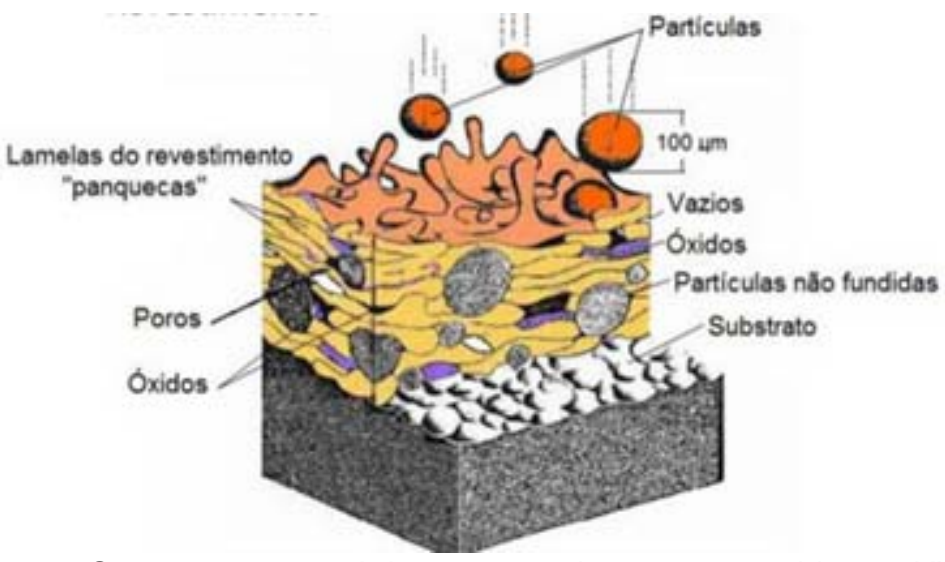

Figura 4. Seção transversal de um revestimento aspergido por HVOF 


\section{MATERIAIS E MÉTODOS}

Para fins de identificação das características metalúrgicas do revestimento, foram realizadas medições de dureza, análises metalográficas e análise química via espectroscopia ótica.

As amostras utilizadas para realização da caracterização metalúrgica foram obtidas a partir de um disco com 40mm de altura e $90 \mathrm{~mm}$ de diâmetro, produzido com o aço ferramenta $\mathrm{H} 13$ e com dureza de $50 \mathrm{HRc}$, sendo o mesmo material e especificação de dureza utilizado na confecção das matrizes deste caso em estudo.

A avaliação de desempenho do revestimento no processo de forjamento a quente foi realizada junto a fabricação de um componente automotivo conhecido como garfo, o qual aplica-se na construção de eixos Cardan. Na figura 5 tem-se uma foto ilustrativa de um garfo forjado, esta peça pesa cerca de $3,8 \mathrm{Kg}$.

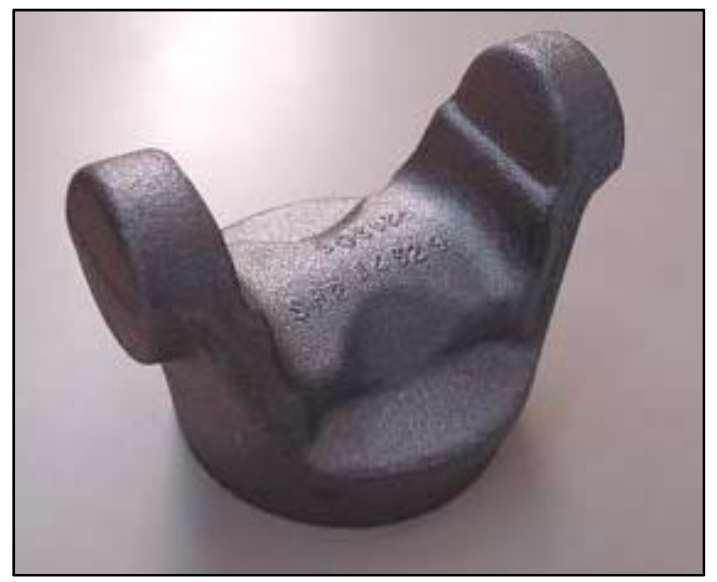

Figura 5. Garfo forjado.

Seguindo os processos convencionais de fabricação e acabamento das ferramentas, o conjunto de matrizes foi revestido por HVOF em separado. O forjamento de um lote com 900 peças foi programado para um conjunto de ferramentas fabricadas na condição convencional e outro lote de 900 peças para as ferramentas revestidas. $\mathrm{Na}$ Figura 6 segue foto ilustrativa do aspecto visual da matriz com acabamento convencional e na Figura 7 o aspecto visual após o processo de aspersão térmica.

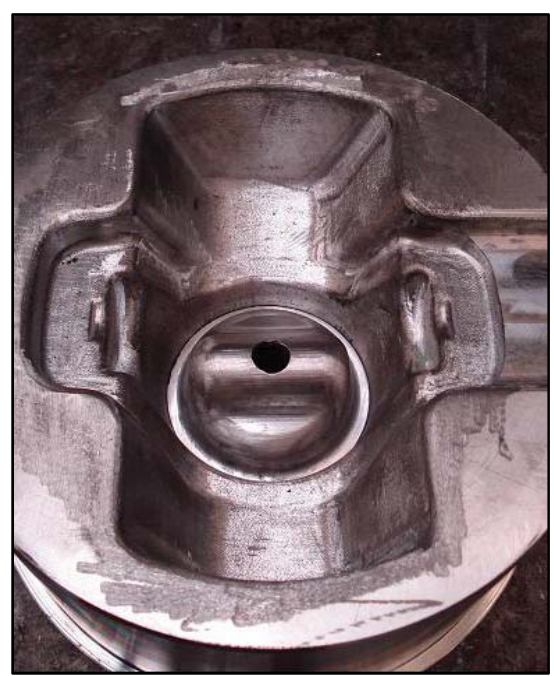

Figura 6. Matriz inferior para forjamento de garfo. Acabamento com retífica manual.

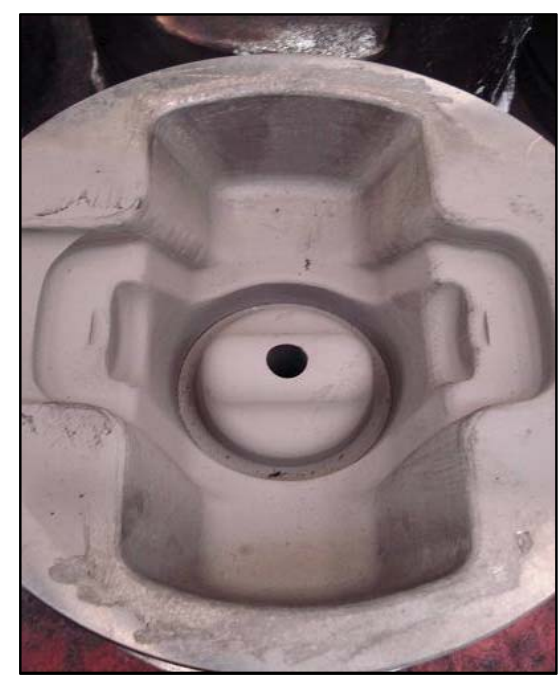

Figura 7. Matriz inferior para forjamento de garfo. Acabamento com retífica manual e posterior recobrimento com asperção térmica. 


\section{RESULTADOS E DISCUSSÃO}

A caracterização de um material e a avaliação de seu desempenho são maneiras eficientes de seleção e especificação de materiais para que as ferramentas sejam utilizadas de maneira produtiva e otimizada. De acordo com os ensaios realizados obteve-se os seguintes resultados.

\subsection{Caracterização Metalúrgica}

Abaixo segue na tabela 1 o resultado da análise química realizada na face superior do revestimento em um equipamento de espectroscopia ótica:

Tabela 1. Análise química do revestimento

\begin{tabular}{|l|c|c|c|c|c|c|c|c|c|c|c|}
\hline $\begin{array}{l}\text { Elementos } \\
\text { Químicos* }\end{array}$ & $\% \mathbf{C}$ & \%Mn & \%Si & \%Al & \%Zn & \%Cr & \%Cu & \%W & \%Ni & \%Co & \%Mo \\
\hline Análise & 0,1 & 0,09 & 0,12 & 0,01 & 2,2 & 6,2 & 0,01 & 81,2 & 0,09 & 9,90 & 0,08 \\
\hline
\end{tabular}

* resultados em porcentagem em massa.

Os resultados da caracterização metalúrgica confirmaram a composição química do filme à base de Tungstênio. Quanto as metalografias foi constatado um filme típico dos processos de aspersão térmica com espessura com cerca de $0,17 \mathrm{~mm}$.

$\mathrm{Na}$ figura 8 é apresentada a microestrutura da interface entre o revestimento e o substrato, é possível observar a porosidade típica deste processo de recobrimento e sua espessura de $0,17 \mathrm{~mm}$. A figura 9 ilustra em detalhe a microestrutura do revestimento, formada por óxidos e partículas agregadas de material fundido e nãofundido.

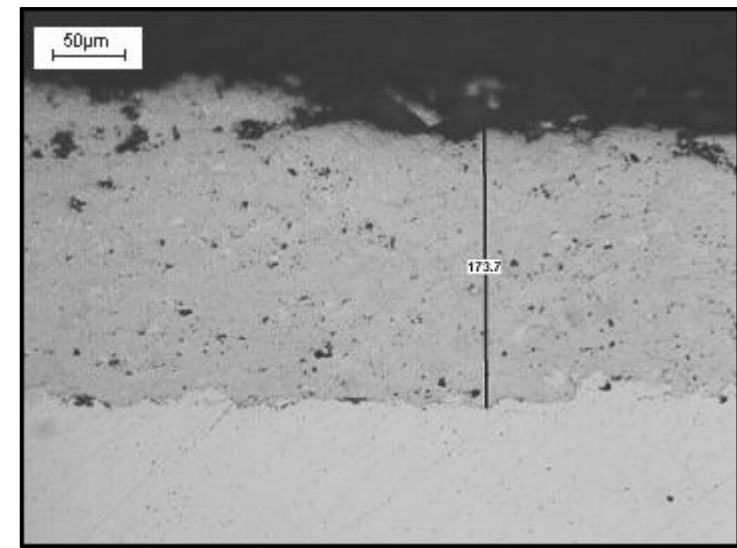

Figura 8. Micrografia da interface entre o revestimento e o substrato

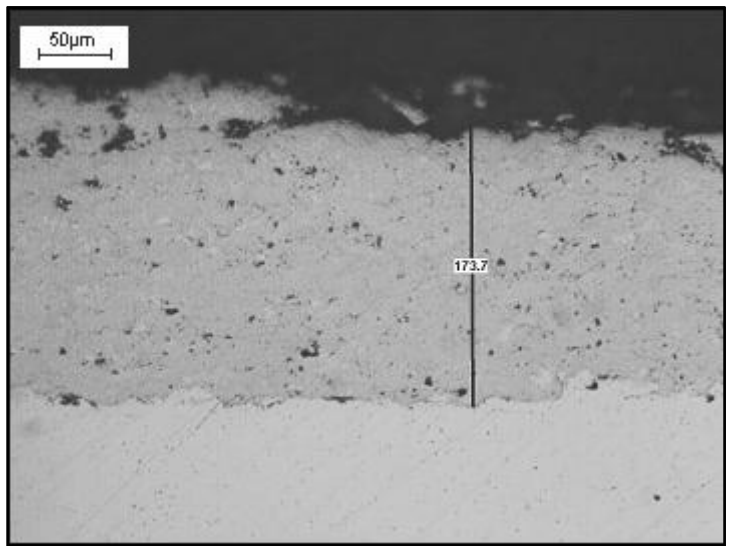

Figura 9. Micrografia em detalhe do revestimento

A tabela 2 mostra o resultado de 8 medições de microdureza realizadas com distâncias de $0,4 \mathrm{~mm}$ ao longo do revestimento.

Tabela 2. Medições de microdureza no revestimento

\begin{tabular}{|c|c|c|c|c|c|c|c|c|c|c|}
\hline Distâncias & $\begin{array}{c}\text { Leitura } \\
\mathbf{1} \\
\mathrm{HV}_{0,2}\end{array}$ & $\begin{array}{c}\text { Leitura } \\
\mathbf{2} \\
\mathrm{HV}_{0,2}\end{array}$ & $\begin{array}{c}\text { Leitura } \\
\mathbf{3} \\
\mathrm{HV}_{0,2}\end{array}$ & $\begin{array}{c}\text { Leitura } \\
\mathbf{4} \\
\mathrm{HV}_{0,2}\end{array}$ & $\begin{array}{c}\text { Leitura } \\
\mathbf{5} \\
\mathrm{HV}_{0,2}\end{array}$ & $\begin{array}{c}\text { Leitura } \\
\mathbf{6} \\
\mathrm{HV}_{0,2}\end{array}$ & $\begin{array}{c}\text { Leitura } \\
\mathbf{7} \\
\mathrm{HV}_{0,2}\end{array}$ & $\begin{array}{c}\text { Leitura } \\
\mathbf{8} \\
\mathrm{HV}_{0,2}\end{array}$ & $\begin{array}{l}\text { Média } \\
\mathrm{HV}_{0,2}\end{array}$ & $\begin{array}{l}\text { Desvio } \\
\text { Padrão }\end{array}$ \\
\hline 0,4 & 801 & 827 & 842 & 819 & 830 & 849 & 813 & 832 & 827 & 15,482 \\
\hline 0.8 & 8 & 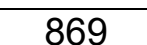 & 9 & 801 & 832 & 850 & 84 & 80 & 836 & 53 \\
\hline & 7 & 8 & 862 & 852 & 86 & 893 & & & 871 & \\
\hline $0,16 \mathrm{~mm}$ & 901 & 897 & 868 & 903 & 896 & 879 & 856 & 907 & 888 & 18,531 \\
\hline
\end{tabular}


Os valores das leituras possuem certa variação, entretanto é possível identificar uma tendência de crescimento a partir da superfície assim como mostra a linha média das oito medições no gráfico 1.

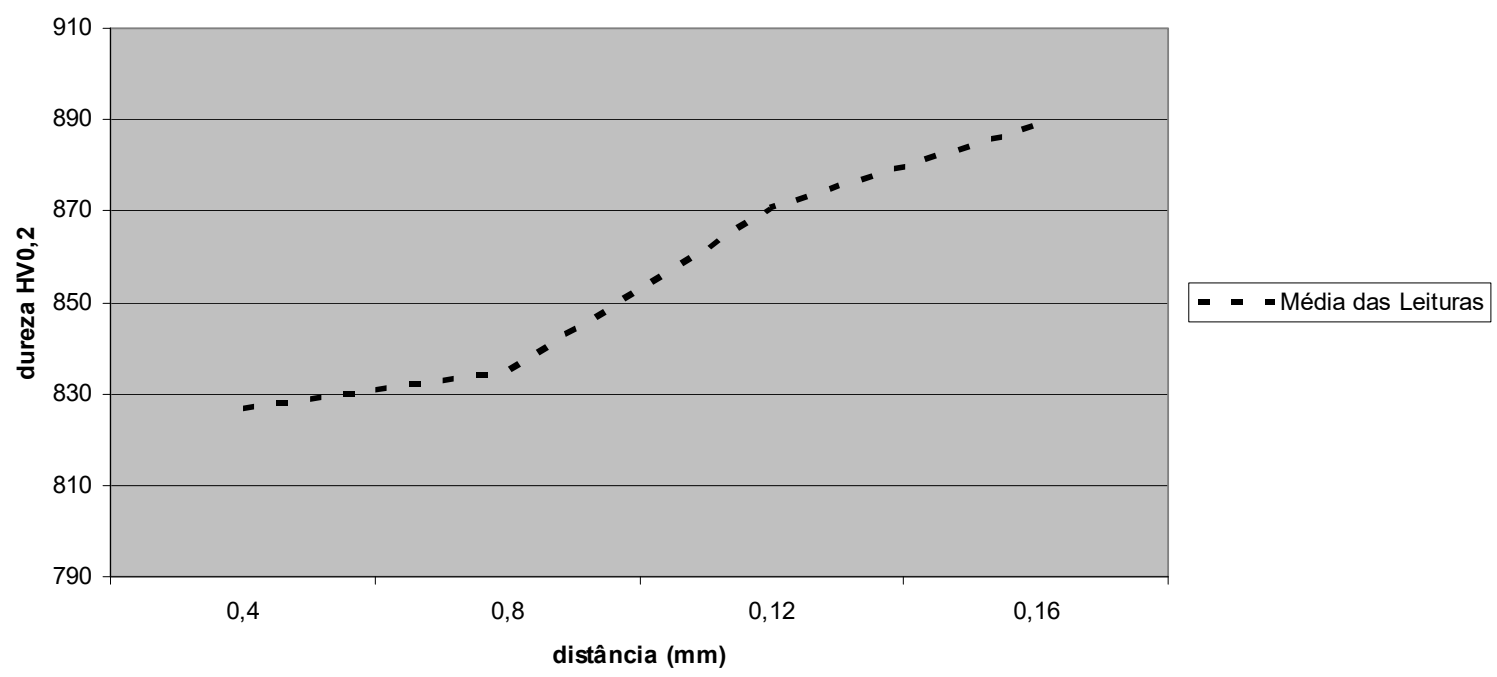

Gráfico 1. Média de 8 medições de microdureza no revestimento.

A variação encontrada nas medições de microdureza está relacionada à porosidade também típica deste processo e condição de deposição do revestimento.

$\mathrm{Na}$ tabela 3 seguem os resultados obtidos na leitura de dureza superficial da amostra citada no item 2 deste artigo.

Tabela 3. Medições de microdureza no revestimento

\begin{tabular}{|c|c|c|c|c|c|c|c|}
\hline $\begin{array}{c}\text { Distâncias } \\
\text { (mm) }\end{array}$ & $\begin{array}{c}\text { Leitura } \\
\mathbf{1} \\
\text { (HRc) }\end{array}$ & $\begin{array}{c}\text { Leitura } \\
\mathbf{2} \\
\text { (HRc) }\end{array}$ & $\begin{array}{c}\text { Leitura } \\
\mathbf{3} \\
\text { (HRc) }\end{array}$ & $\begin{array}{c}\text { Leitura } \\
\mathbf{4} \\
\text { (HRc) }\end{array}$ & $\begin{array}{c}\text { Leitura } \\
\mathbf{5} \\
\text { (HRc) }\end{array}$ & $\begin{array}{c}\text { Médias } \\
\text { (HRc) }\end{array}$ & $\begin{array}{c}\text { Desvio } \\
\text { Padrão }\end{array}$ \\
\hline $\mathbf{0 - 3 0}$ & 66 & 64 & 65 & 67 & 65 & 65,4 & 1,140 \\
\hline $\mathbf{3 0 - 6 0}$ & 65 & 67 & 65 & 67 & 66 & 67 & 1,000 \\
\hline $\mathbf{6 0 - 9 0}$ & 65 & 65 & 65 & 66 & 66 & 67 & 0,548 \\
\hline
\end{tabular}

\subsection{Teste de desgaste método Esfera-Sobre-Disco}

Com o objetivo de avaliar o desempenho do tratamento superficial desenvolvido foi realizado o teste da esfera-sobre-disco. Este ensaio fornece informações do atrito e da resistência ao desgaste sob condições de deslizamento. Situação encontrada na grande maioria de operações com ferramentas em que há o contato entre peça de trabalho (simulada pela esfera) e ferramenta (simulada pelo disco).

Os resultados apresentados nos Gráficos 2 e 3 mostram que o coeficiente de atrito foi maior com a superfície na condição convencional com valor médio de 0,66 em comparação com valor médio de 0,42 obtido na superfície revestida. Esta diferença indica que o revestimento possui boa tenacidade, boa adesão ao substrato e elevada dureza. 


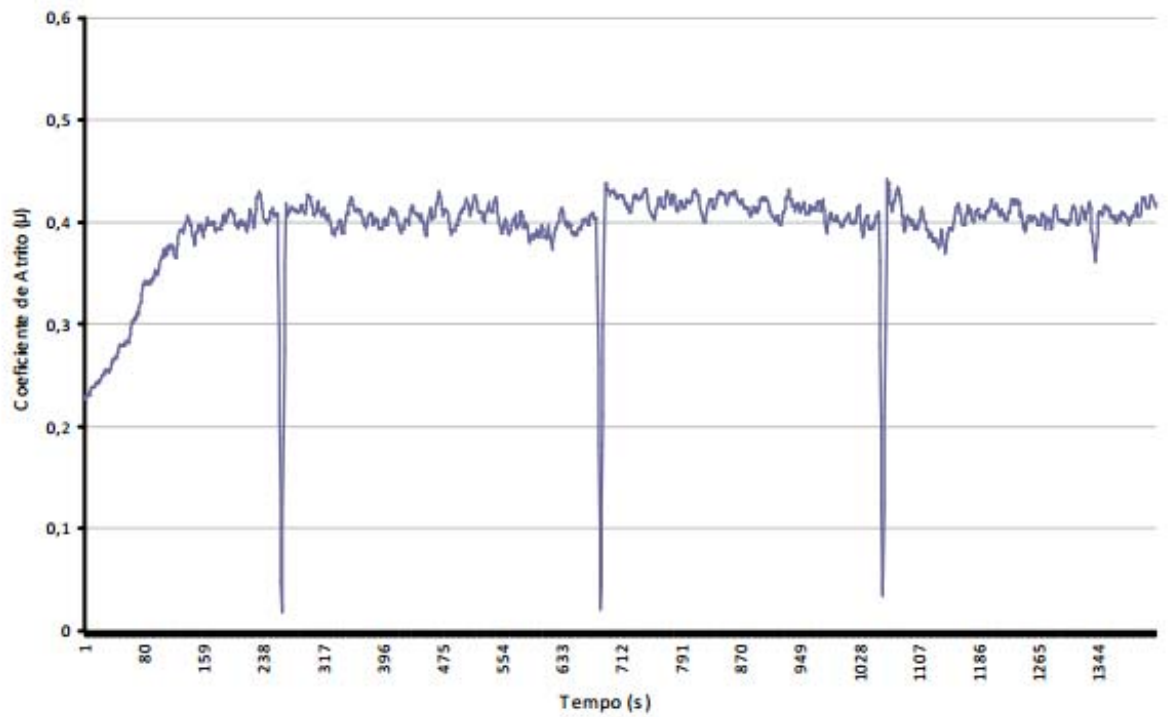

Gráfico 2. Comportamento do coeficiente de atrito obtido na superfície com o revestimento.

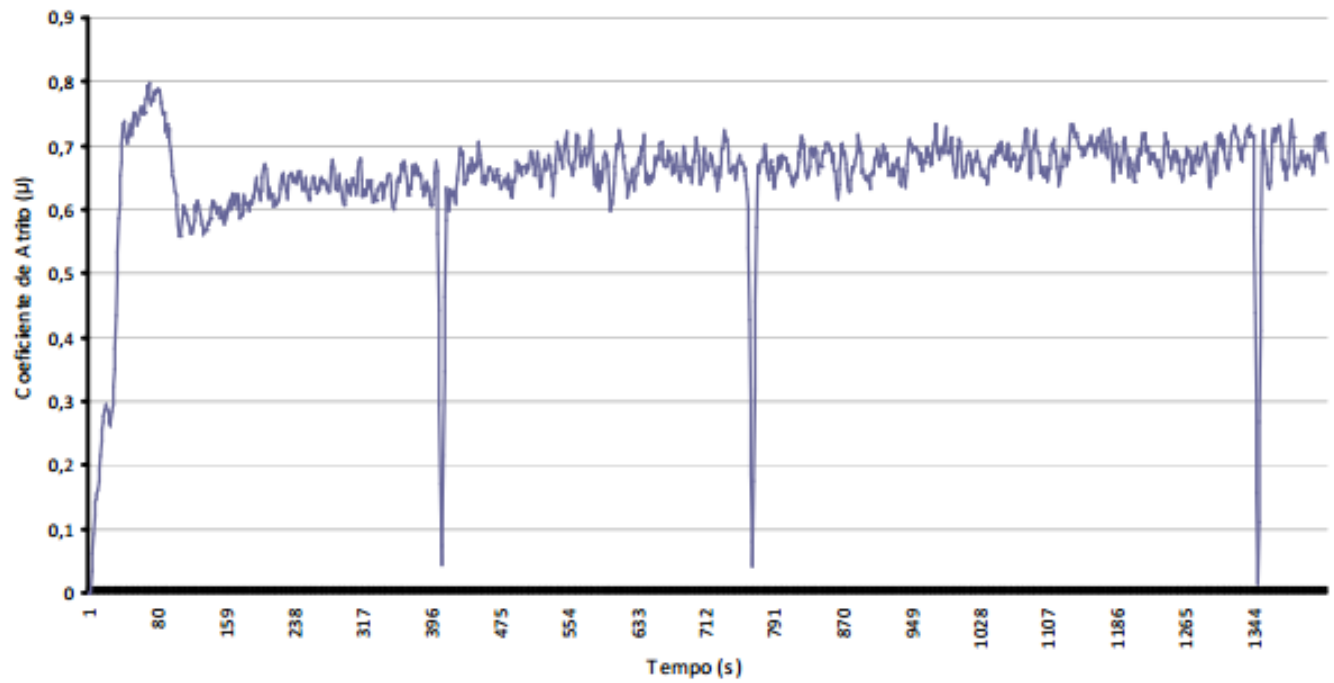

Gráfico 3. Comportamento do coeficiente de atrito obtido na superfície da condição convencional.

Através do ensaio de desgaste em laboratório é possível observar valores do coeficiente de atrito de 4,2 na superfície com a camada depositada, o qual é menor que o valor de 6,6 obtidos na superfície da condição convencional de fabricação. De forma qualitativa a amostra com revestimento mostrou menos desgaste no teste do pino-disco.

\subsection{Desempenho da matriz revestida na produção}

Na tabela 4 está apresentado o comparativo entre os resultados de produção obtidos com a ferramenta convencional e o lote forjado com a ferramenta revestida.

Através dos resultados apresentados na tabela 4 é possível observar que o forjamento com a ferramenta revestida possibilitou um aumento na produção em $37,5 \%$ se comparado com o processo convencional, ou seja, sem o revestimento. O tempo de produção mostrou melhores resultados, pois houve redução de $75 \%$ em situações na qual a máquina permaneceria parada. 
Tabela 4. Resultados dos testes em produção

\begin{tabular}{|c|c|c|c|}
\hline Atividades & $\begin{array}{l}\text { Ferramentas } \\
\text { com } \\
\text { Revestimento }\end{array}$ & $\begin{array}{l}\text { Ferramentas } \\
\text { na Condição } \\
\text { Convencional }\end{array}$ & $\begin{array}{c}\text { Diferença, } \\
\text { Considerando a } \\
\text { Condição } \\
\text { Convencional } \\
\text { como Referência }\end{array}$ \\
\hline $\begin{array}{c}\text { Número total de peças } \\
\text { forjadas (quantidade } \\
\text { em peças) }\end{array}$ & 1386 & 1008 & +378 \\
\hline $\begin{array}{l}\text { Sucata devido a } \\
\text { problemas } \\
\text { relacionados à } \\
\text { ferramenta } \\
\text { (quantidade em } \\
\text { peças) }\end{array}$ & 0 & 5 & -5 \\
\hline $\begin{array}{c}\text { Tempo perdido de } \\
\text { produção devido a } \\
\text { problemas ou } \\
\text { suspeitas relativos às } \\
\text { ferramentas (minutos) }\end{array}$ & 9 & 36 & -27 \\
\hline $\begin{array}{l}\text { Incidentes de } \\
\text { qualidade } \\
\text { relacionados às } \\
\text { ferramentas } \\
\text { (quantidade de casos) }\end{array}$ & 0 & 2 & -2 \\
\hline $\begin{array}{l}\text { Suspeitas de } \\
\text { problemas de } \\
\text { qualidade } \\
\text { relacionados às } \\
\text { ferramentas } \\
\text { (quantidade de casos) }\end{array}$ & 1 & 3 & -2 \\
\hline
\end{tabular}

As matrizes revestidas apresentaram melhor desempenho em relação a qualidade das peças e também no quesito produtividade onde podemos verificar na tabela 4 nas atividades de sucata e ferramental. Nas figuras 10 e 11 seguem fotos de peças pertencentes ao final do lote programado de 900 peças, observa-se claramente melhor legibilidade da gravação na condição com as ferramentas revestidas.

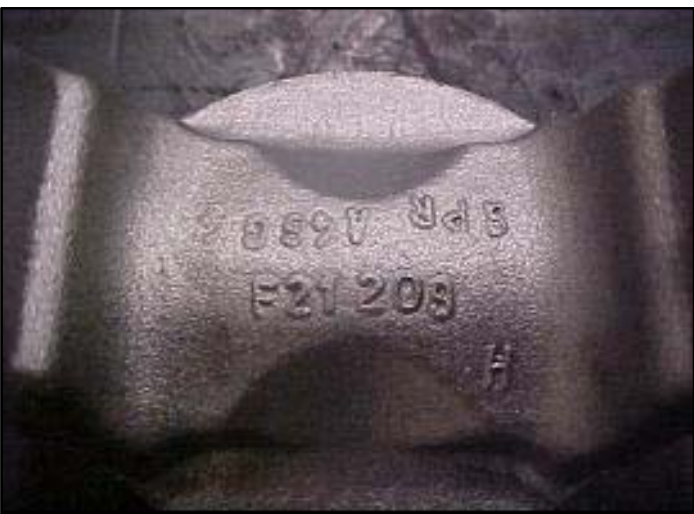

Figura 10. Foto de peça forjada no final do lote com matrizes revestidas

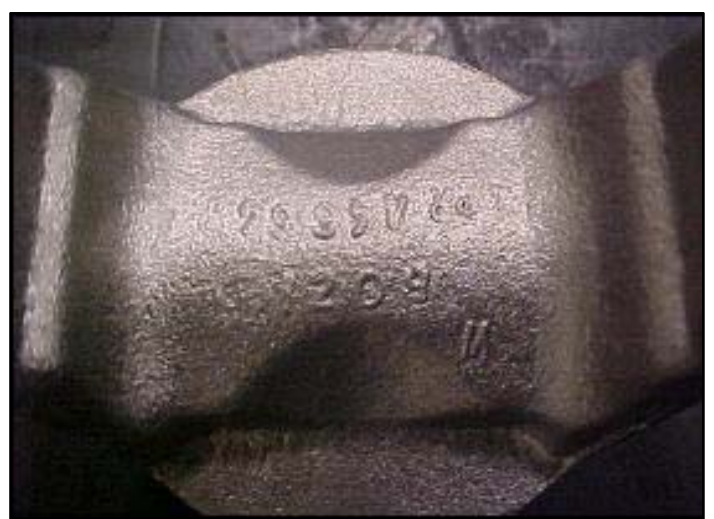

Figura 11. Foto de peça forjada no final do lote com matrizes na condição convencional 
O comportamento das matrizes revestidas é mais estável quanto aos requisitos de fabricação e este aspecto possibilitou melhor desempenho de todos os fatores relacionados a produtividade.

\section{CONCLUSÃO}

No teste em produção, as ferramentas revestidas apresentam uma melhora significativa no desempenho, a quantidade de peças produzidas foi cerca de $35 \%$ superior em comparação com as ferramentas convencionais. Aspectos referentes à qualidade também apresentam melhores resultados no forjamento com as ferramentas revestidas. Com base nos resultados obtidos após a fabricação de um lote de peças é possível concluir que, referente aos aspectos financeiros, o processo de fabricação das peças com as matrizes revestidas por HVOF apresentam lucro aproximado de $30 \%$ se comparadas com o processo convencional.

\section{Agradecimentos}

Os autores agradecem a divisão de forjados da Dana Albarus de Gravataí e a empresa Rijeza de São Leopoldo pela disponibilidade para realização dos testes em produção e análises de laboratório. Assim como à CAPES e CNPQ pelas bolsas de pesquisa.

\section{REFERÊNCIAS}

1 Huff JA. Avaliação do desempenho de matrizes para forjamento a quente revestidas por carboneto de cromo através do processo HVOF. Porto Alegre: Mestrado UFRGS/PPGE3M; 2009.

2 Lima CC, Trevisan R. Aspersão térmica - Fundamentos e aplicações. São Paulo: Artliber; 2007.

3 Byrer TG. ASM - Forging Handbook - Introduction and applications. Cleveland: Forging Industry Association; 1985.

4 Schneider KE, Belashchenko V, Dratwinski M, Siegmann S, Zagorski A. Thermal spraying for power generation components. Weinheim: Wiley-VCH Verlag Gmbh \& Co. KgaA; 2006.

5 Fauchais PL, Heberlein JV, Boulos MI. Thermal spray fundamentals. New York: Springer; 2014. 